\title{
Awareness and Usage of Computer and Internet among Medical Faculties' Students at the University of Jordan
}

\author{
Tamara Almarabeh, Lama Rajab, Yousef Kh. Majdalawi \\ Computer Information Systems Department, The University of Jordan, Amman, Jordan \\ Email: t.almaraabeh@ju.edu.jo, lama.rajab@ju.edu.jo, ymajdal@ju.edu.jo
}

Received 1 April 2016; accepted 8 May 2016; published 11 May 2016

Copyright (C) 2016 by authors and Scientific Research Publishing Inc.

This work is licensed under the Creative Commons Attribution International License (CC BY).

http://creativecommons.org/licenses/by/4.0/

(c) (i) Open Access

\begin{abstract}
The rapid development of information communication technology blazed a trail in our learning, work, and lives. This study was conducted to ascertain the computer and internet literacy level of medical faculties' students. 171 first-year medical students from 4 different medical colleges of the University of Jordan participated in the study. A semi-structured questionnaire was used to collect the data and the data analysis was done by using SPSS, Version 17. The results indicated that most medical students have average 5 or advance knowledge on the basic use of computer and internet. Google was found to be the most commonly used search engine. Also the study found that ICT (Information and Communication Technology) can be a useful tool in medical education but the lack of time, internet connectivity and resources is still a serious constraint.
\end{abstract}

\section{Keywords}

ICT, Jordan, Internet, Attitudes, Literacy

\section{Introduction}

No one can deny that ICT in medical education is not only a tool, but also a goal; but to construct a better doctor, a better nurse, a better pharmacist, etc., it has to be properly aware of the computers, internet and how to access better and more information via electronic ways. ICT has changed the ways in which medicine is practiced and taught [1]. The internet has become the world's biggest library, where the retrieval of scientific resources can be done within minutes [2].

The adoption of ICT in universities was required by the continual review of the curriculum which invariably requires access to a variety of information sources and types by students and teachers [3]. 
The use of computers as a learning tool in the medical and dental education dates back to the early 1970s [4] and its introduction was at the University of Kentucky [5]. The utilization of internet services in any university would depend upon the percentage of the students who know how to operate a computer as well as take advantage of the various online services. Therefore, the current study was carried out to find out the use of computers and the internet and the purpose of using the internet among the medical faculties' students of the University of Jordan.

\section{Literature Review}

Virpi Slotte et al. (2001) [6], the research was conducted in Finland. The aim of the national "IT Culture in Medical Education” project there is to enhance the opportunities new technology may provide for medical education. And find out what attitudes medical teachers and medical students have towards IT and how information and communication technology is currently used in medical education. Data were collected by means of a questionnaire designed to gather information about IT use in medical education, sent to teachers and students in two universities. Results: In both universities appeared that medical teachers and students had a very positive attitude toward the advances in modern technology. Medical students emphasized the importance in a physician's work of being able to use information technology. They would also be willing to study clinical cases electronically, but considered that the medical faculty should provide more computers for them.

Parveen Kumar (2012) [7], the study was conducted to ascertain the computer literacy level of medical students. Its results indicated that most medical students have some average or advance knowledge on the basic use of computer software that is Microsoft-word, excel, internet, email, etc. The study found that ICT can be a useful tool in overcoming problems in medical education, but the lack of technology and resources is still a serious limitation.

Nurjahan et al. (2002) [8], obtain a self-reported assessment of the use of ICT by medical students at the International Medical University, Malaysia. Students' perceived skills and extent of usage of ICT were evaluated using a questionnaire. The questionnaire revealed that Twenty seven students (5.7\%) did not use a computer either in the university or at home. Most students surveyed reported adequate skills at word processing (55\%), e-mailing (78\%) and surfing the internet (67\%). The results suggests that in order to increase the level of computer literacy among medical students, positive steps would need to be taken, for example the formal inclusion of ICT instruction in the teaching of undergraduate medicine. This will enhance medical students' ability to acquire, appraise, and use information in order to solve clinical and other problems quickly and efficiently in the course of their studies, and more importantly when they graduate.

\section{Methodology}

The present study was carried out at the University of Jordan among the students of the faculty of medicine, faculty of nursing, faculty of pharmacy, faculty of dentistry, and faculty of rehabilitation sciences, who included male and female students, who registered in computer skills for medical students course during February 2016 to April 2016. This course is a compulsory course for the medical faculties' students. The collected data were analyzed and presented in the form of tables and charts. Results were reported in percentages. The study was undertaken using first year undergraduate students. The aim for this research is to identify the basic skills in using computer and internet. The questions for this study are adopted from previous researches [9]-[11] with modifications. The questions were divided in two groups; the first group contains the sample demographics which are shown in Table 1 . The second group contains 11 questions spread over 3 sections:

(A) Awareness of ICT Literacy of Medical Students and Their Attitudes. (B) Use of Computer and Internet by Medical Students and (C) Constraints in Use of ICT.

\section{Discussion}

It was observed that majority 97\% first started using computer and internet before joining medical college while $3 \%$ started after joining medical college as shown in Table 1.

\section{(A) Awareness of ICT Literacy of Medical Students and Their Attitudes}

ICT literacy focuses on bridging the ideas of information literacy and technology literacy. It focuses on how students locate, organize and communicate information with digital environments [12]. The survey found that a 
Table 1. Sample demographics.

\begin{tabular}{|c|c|c|c|}
\hline Category & Characteristics & Number & Percentage \\
\hline \multirow{4}{*}{ GPA } & Excellent & 94 & $54.97 \%$ \\
\hline & Very good & 49 & $28.65 \%$ \\
\hline & Good & 26 & $15.20 \%$ \\
\hline & Fair & 2 & $1.17 \%$ \\
\hline \multirow{2}{*}{ Gender } & Male & 38 & $22.22 \%$ \\
\hline & Female & 133 & $77.78 \%$ \\
\hline \multirow{5}{*}{ Faculty } & Faculty of medicine & 21 & $12.28 \%$ \\
\hline & Faculty of nursing & 18 & $10.53 \%$ \\
\hline & Faculty of pharmacy & 63 & $36.84 \%$ \\
\hline & Faculty of dentistry & 51 & $29.82 \%$ \\
\hline & Faculty of rehabilitation sciences & 18 & $10.53 \%$ \\
\hline \multirow{2}{*}{ First Use of Computer? } & Before joining medical faculty & 166 & $97.08 \%$ \\
\hline & After joining medical faculty & 5 & $2.92 \%$ \\
\hline
\end{tabular}

majority of respondents believe that ICT is essential for medical education. In order to assess the attitudes towards ICT, they were asked whether they felt that medical education would be effective without ICT and asked if they feel that the internet has positive effect on their academic performance. $77 \%$ of respondents agree that the medical education will not be effective without ICT tools as shown in Figure 1. 91\% of students agree that the internet has a positive impact on academic performance as in Figure 2.

(B) Use of Computer and Internet by Medical Students

Computers and the Internet are revolutionizing the process of education at all levels. Computers are not only becoming key tool in the educational process, they also make education available in places and at times in which it was previously inaccessible [13]. The state of computer and internet use by the students is very encouraging. This encourage might due to affordability and also the easy availability of new generation of mobiles from which internet can be accessed and they can be carried easily. Figure 3 and Figure 4 summarize the purpose and the frequency of using Internet. Sharma et al. [14] which reported that a majority of the undergraduate medical students used the internet for entertainment and this study found the same result while Jadoon et al. [15] stated that $61.0 \%$ used the internet for both academic and Personal activities, while $17 \%$ used it for academic activities. Figure 5 shows the purpose of using the Internet in the medical field among the medical students at the University of Jordan.

While evaluating the students' computer and internet literacy, most of the students consider themselves (71\%) as an average user. $15 \%$ considered themselves as experts and $11 \%$ as beginners. Few of them (3\%) are unfamiliar with using computer and internet as you see in Figure 6.

The preferred medium for getting information among the students in the present study was the internet then followed by textbook as in Figure 7. This indicates that the use of internet is increasing for getting required information. Unnikrishnan et al. [16] showed similar results whereas the studies by Sharma et al. [14] showed that the textbook was preferred medium for most of the undergraduate medical students. Most of the students referred the reason for preferring internet is the ease of accessibility followed by time saving as shown in Figure 8.

The present study revealed that the common accessed website is Google, followed by Social networking Sites, Yahoo, and PubMed as in Figure 9. Studies which were conducted in India [16] and Sudan [17] showed that a small percentage of the medical students accessed PubMed due to a lack of knowledge on the basic technological aspects of the Internet and confuses to the database for searching to getting medical information.

When asking the students if they are confident for using the applications of computer. 40\% use E-mail followed by MS-PowerPoint software for preparing presentations as shown in Figure 10. 
Do you feel the medial education will be effective without use of ICT tools and techniques?

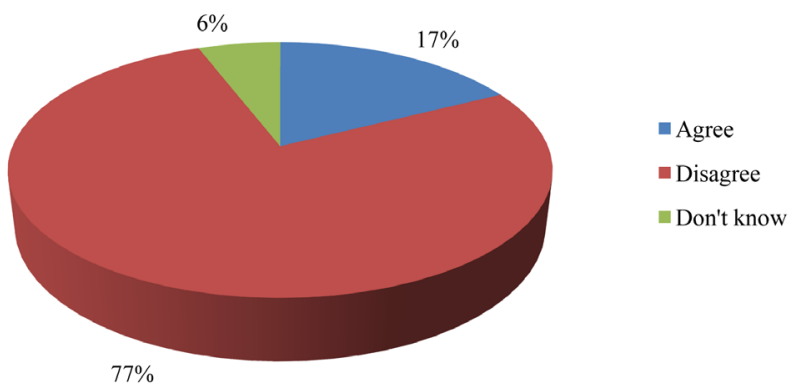

Figure 1. Effectiveness of ICT tools on the medical education.

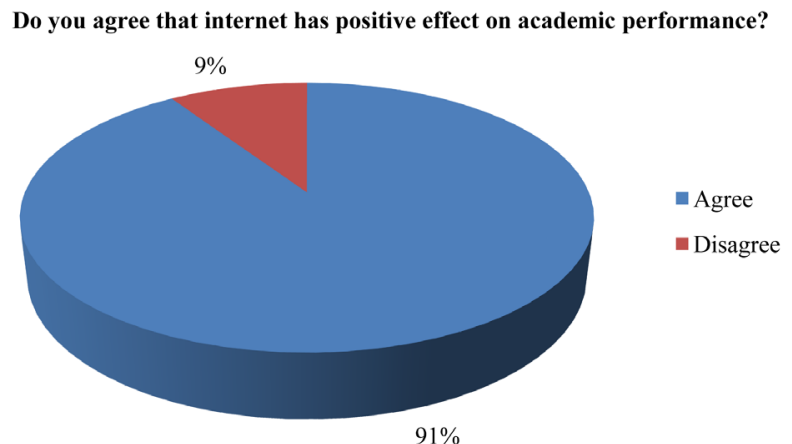

Figure 2. The positive effect of the internet on academic performance.

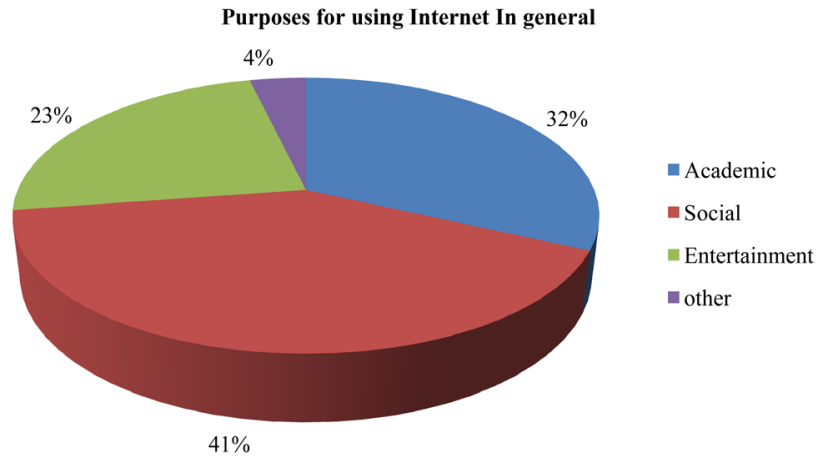

Figure 3. Purposes for using internet In general.

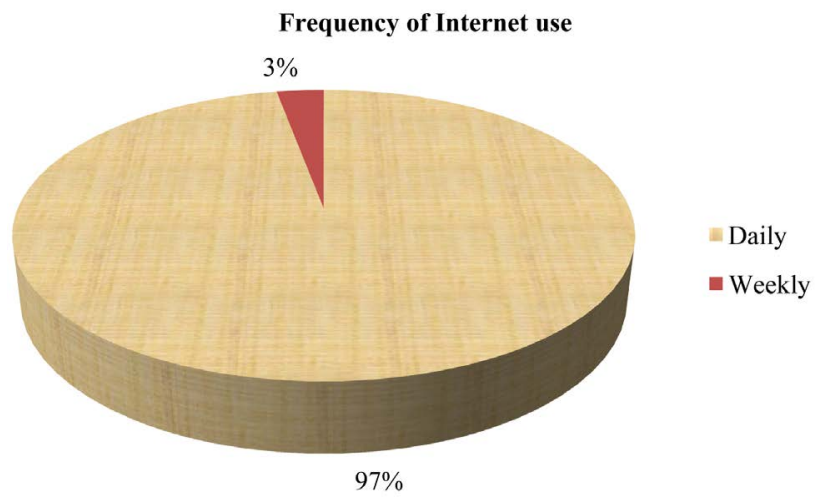

Figure 4. Frequency of internet use. 


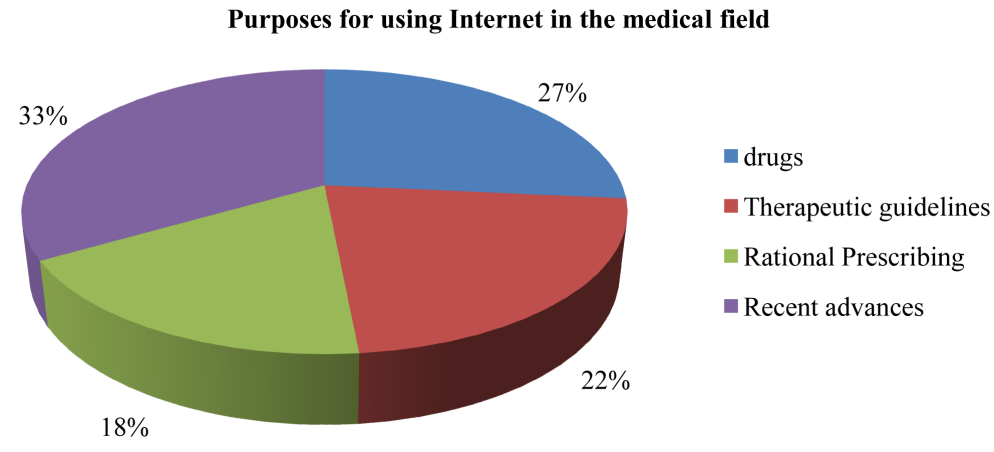

Figure 5. Purposes for using internet in the medical field.

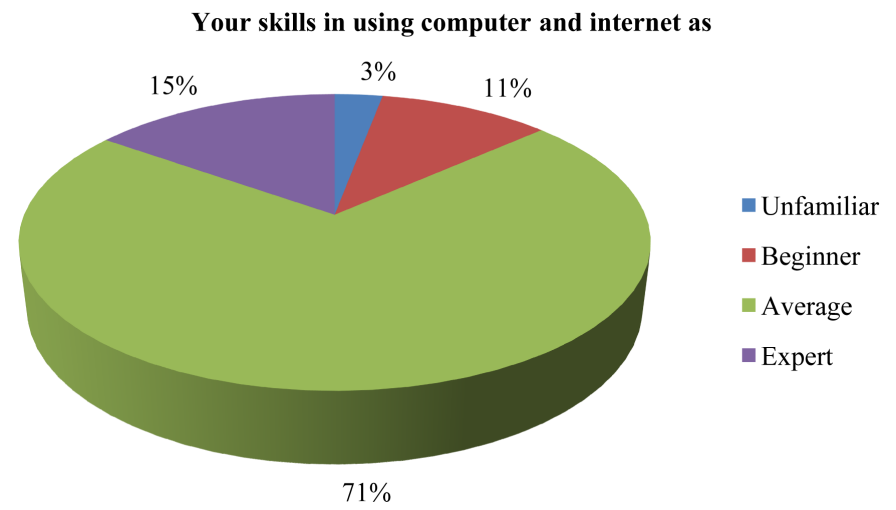

Figure 6. Skills in using computer and internet.

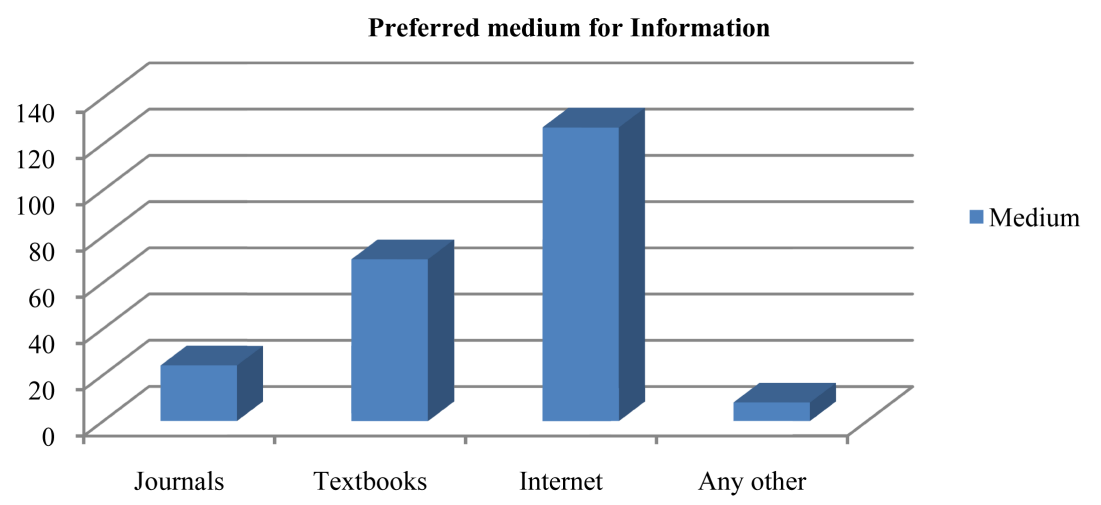

Figure 7. Preferred medium for information.

Reasons for Preferring Internet

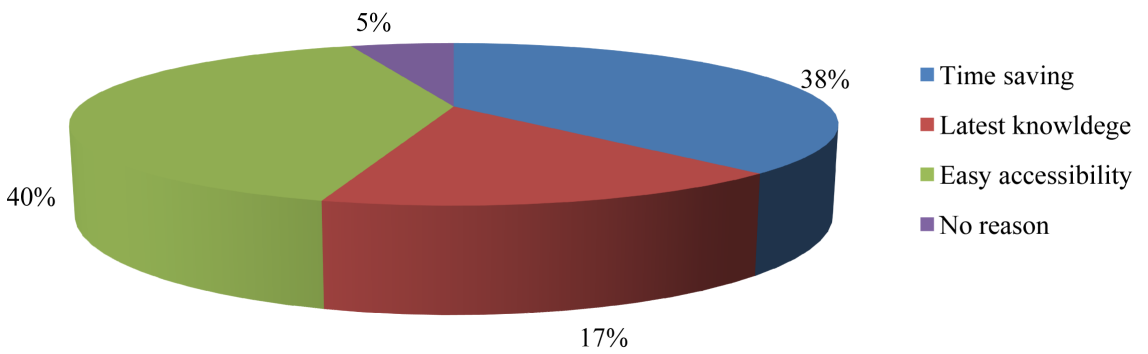

Figure 8. Reasons for preferring internet. 


\section{(C) Constraints in Use of ICT}

There are many obstacles facing students when using ICT at the University of Jordan. Some of those obstacles are related to the lack of time to use the internet followed by no or weak internet connectivity which shown in Figure 11 in details.

The researchers in Table 2 compared some of this study results with other studies to determine the status of the University of Jordan medical students in this study with previous studies.

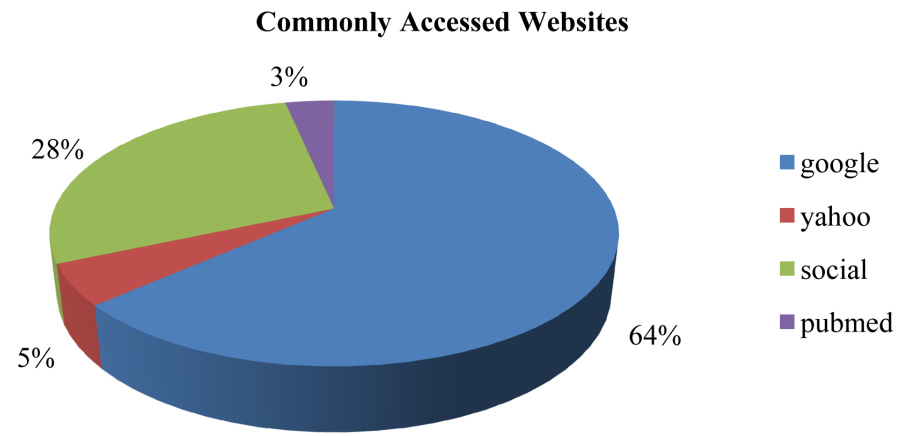

Figure 9. Commonly accessed websites.

Which of the following applications you can work on?

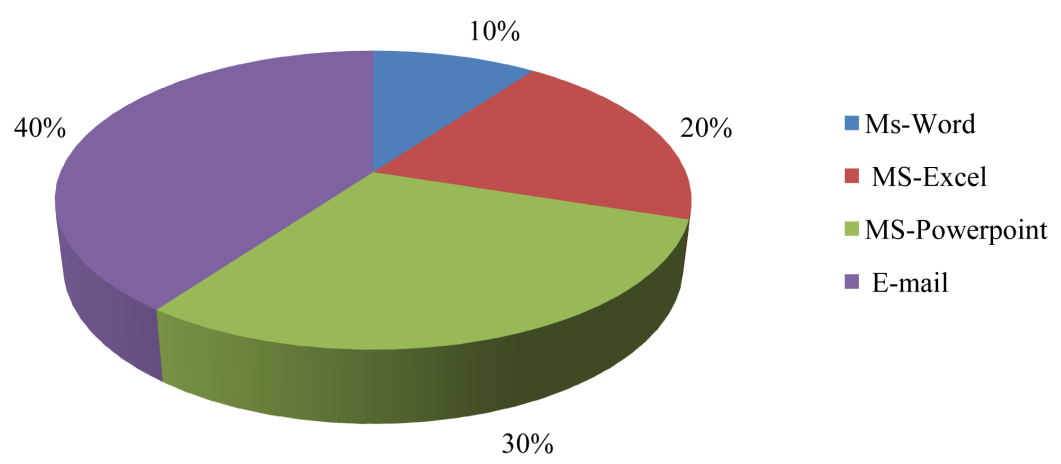

Figure 10. Medical students’ confidence of different computer applications.

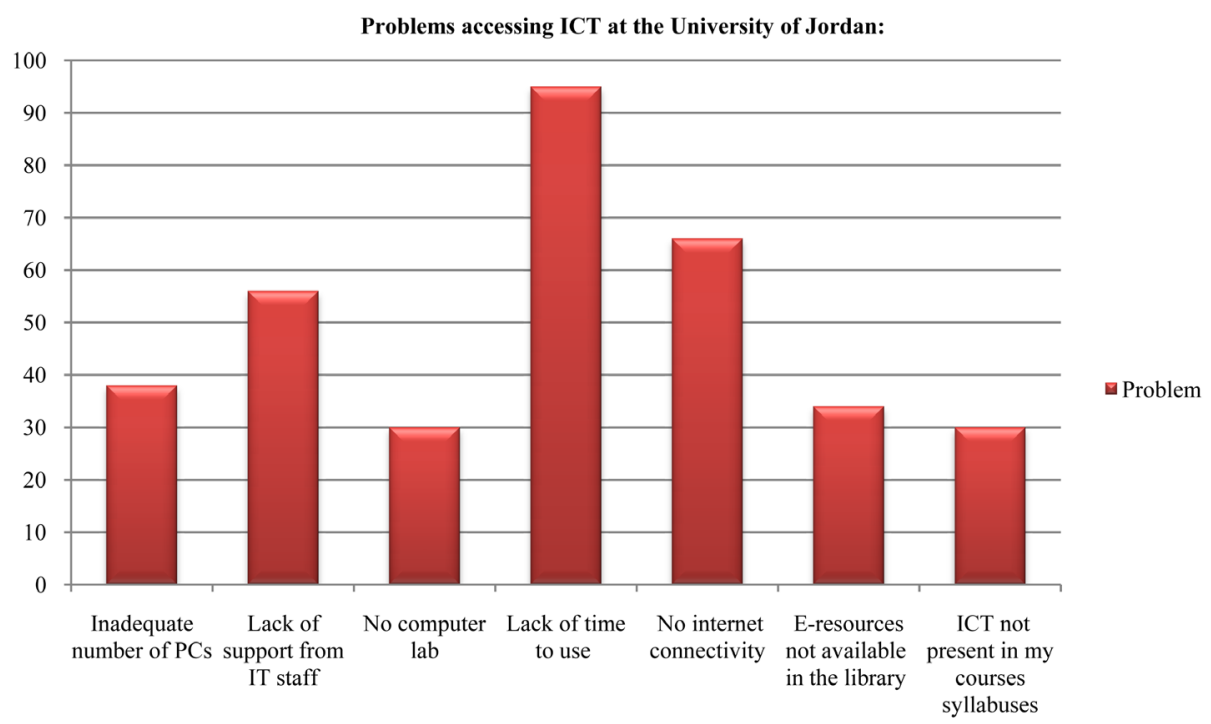

Figure 11. Problems accessing ICT at the University of Jordan. 
Table 2. Comparison between present study and other studies.

\begin{tabular}{|c|c|c|c|}
\hline Studies & $\begin{array}{l}\text { Use of the search } \\
\text { engine Google }\end{array}$ & $\begin{array}{l}\text { Academic/professional } \\
\text { purpose of computer }\end{array}$ & $\begin{array}{c}\text { Internet as } \\
\text { information source }\end{array}$ \\
\hline Present Study (the University of Jordan) & $64 \%$ & $32 \%$ & $55.46 \%$ \\
\hline Ranasinghe et al. [18] & - & $100 \%$ & - \\
\hline Seetharaman N. [19] & $48.9 \%$ & $57.1 \%$ & $62.9 \%$ \\
\hline Jadoon et al. [15] & $88.9 \%$ & $17 \%$ & - \\
\hline Unnikrishnan B et al. [16] & $60.2 \%$ & $12.8 \%$ & $38.8 \%$ \\
\hline Ahmed et al. [17] & - & $29.3 \%$ & - \\
\hline Sharma et al. [14] & 34.66 & $80 \%$ & $36 \%$ \\
\hline Ajuwon GA [20] & $9 \%$ & - & 48.6 \\
\hline Mansor I [21] & - & $37.5 \%$ & $78 \%$ \\
\hline
\end{tabular}

\section{Conclusion}

The current study evaluated the awareness and utilization of ICT among the medical students at the University of Jordan. With the development of ICT, computer and internet are likely to play a more important role in many medical fields in the future so the decision makers at the university should pay attention to overcome the problems faced by the students which lead to improving the access to the computer and internet beside the required skills for using them.

\section{Acknowledgements}

The authors would like to thank all the medical students who participated in this study and acknowledge the immense help which was received from the scholars whose articles have been cited and included among the references.

\section{References}

[1] Thierry, K. and Bernard, C. (2008) Information and Communication Technologies (ICT) in Medical Education and Practice: The Major Challenges. International Journal of Technology and Design Education, 5, 68-81.

[2] Yadav, H., Jain, S., Kapila, S. and Prasad, G. (2005) Internet Resources for Diabetes. Indian Journal of Medical Sciences, 59, 32-42. http://dx.doi.org/10.4103/0019-5359.13818

[3] Oliver, R. (2002) The Role of ICT in Higher Education for the 21st Century: ICT as a Change Agent for Education. http://citeseerx.ist.psu.edu/viewdoc/download?doi=10.1.1.83.9509\&rep=rep1\&type=pdf

[4] Smith, W., Bedayse, S., Lalwah, S.L. and Paryag, A. (2009) Computer Literacy and Attitudes of Dental Students and Staff at the University of the West Indies Dental School. European Journal of Dental Education, 13, 179-183. http://dx.doi.org/10.1111/j.1600-0579.2009.00571.x

[5] Rajab, L.D. and Baqain, Z.H. (2005) Use of Information and Communication Technology among Dental Students at the University of Jordan. Journal of Dental Education, 69, 387-398.

[6] Slotte, V., Wangel, M. and Lonka, K. (2001) Information Technology in Medical Education: A Nationwide Project on the Opportunities of the New Technology. Medical Education, 35, 990-995.

http://dx.doi.org/10.1111/j.1365-2923.2001.01023.x

[7] Kumar, P. (2012) Application of Information and Communication Technology (ICT) by Medical Students: A Study of Government Medical College, Chandigarh, India. International Journal of Library and Information Science, 4, 45-51

[8] Nurjahan, M.I., Lim, T.A., Yeong, S.W., Foong, A.L. and Ware, J. (2002) Utilization of Information Technology in Medical Education: A Questionnaire Survey of Students in a Malaysian Institution. Medical Journal of Malaysia, 57, 58-66.

[9] Hamissi, J., Gholami, S. and Hamissi, H. (2012) Evaluation of Information and Communication Technology Knowledge among Undergraduate Dental Students in Iran. Asian Journal of Computer Science and Information Technology, 8, 247-250. 
[10] Challa, N. and Madras, V. (2014) Attitude, Awareness and Usage Skills of Computer and Internet among Medical Students. IOSR Journal of Dental and Medical Sciences (IOSR-JDMS), 13, Ver. IV.

[11] Aldebasi, Y. and Ahmed, M.I. (2013) Computer and Internet Utilization among the Medical Students in Qassim University, Saudi Arabia. Journal of Clinical and Diagnostic Research, 7, 1105-1108. http://dx.doi.org/10.7860/JCDR/2013/5891.3092

[12] Katz, I.R. (2005) Beyond Technical Competence: Literacy in ICT. Education Technology Magazine, 45, 144-147.

[13] Schleyer, T.K.L. (1999) Digital Dentistry in the Computer Age. The Journal of the American Dental Association, 130, 1713-1719. http://dx.doi.org/10.14219/jada.archive.1999.0127

[14] Sharma, R., Verma, U., Sawhney, V., Arora, S. and Kapoor, V. (2006) Trend of Internet Use among Medical Students. JK Science: Journal of Medical Education \& Research, 8, 101-102.

[15] Jadoon, N.A., Zahid, M.F., Mansoorulhaq, H., Ullah, S., Jadoon, B.A., Raza, A., et al. (2011) Evaluation of Internet Access and Utilization by Medical Students in Lahore, Pakistan. BMC Medical Informatics and Decision Making, 11, 37. http://dx.doi.org/10.1186/1472-6947-11-37

[16] Unnikrishnan, B., Kulshrestha, V., Saraf, A., Agrahari, A.C., Prakash, S., Samantaray, L. and Parida, A. (2008) Pattern of Computer and Internet Use among Medical Students in Coastal South India. South East Asian Journal of Medical Education, 2, 18-25.

[17] Ahmed, A.M., Yousif, E. and Abdalla, M.E. (2008) Use of the Internet by Sudanese Doctors and Medical Students. Eastern Mediterranean Health Journal, 14, 134-141.

[18] Ranasinghe, P., Wickramasinghe, S.A., Pieris, W.R., Karunathilake, I. and Constantine, G.R. (2012) Computer Literacy among First Year Medical Students in a Developing Country: A Cross Sectional Study. BMC Research Notes, 5, 504. http://dx.doi.org/10.1186/1756-0500-5-504

[19] Seetharaman, N. (2012) Assessing Computer Skills among Graduate Medical Students in South India. National Journal of Community Medicine, 1, 1-60.

[20] Ajuwon, G.A. (2003) Computer and Internet Use by First Year Clinical and Nursing Students in a Nigerian Teaching Hospital. BMC Medical Informatics and Decision Making, 3, 10. http://dx.doi.org/10.1186/1472-6947-3-10

[21] Mansoor, I. (2002) Computer Skills among Medical Learners: A Survey at King Abdul Aziz University, Jeddah. Journal of Ayub Medical College, Abbottabad: JAMC, 14, 13-15. 